\title{
Impact of Knowledge Management Strategies on Organizational Performance in the Hospitality Industry of Zimbabwe
}

\author{
Mildred Mahapa ${ }^{1}$ \\ ${ }^{1}$ Human Resource Management Department, Midlands State University, Gweru, Zimbabwe \\ Correspondence: Mildred Mahapa, Human Resource Management Department, Midlands State University, \\ Gweru, Zimbabwe. Tel: 26-377-929-7472/26-371-203-3420. E-mail: mupandarem@msu.ac.zw
}

Received: August 1, 2012 Accepted: October 9, 2012 Online Published: April 24, 2013

doi:10.5539/par.v2n1p76 URL: http://dx.doi.org/10.5539/par.v2n1p76

\begin{abstract}
The research identifies the knowledge management strategies and how they impact on organizational performance in the hospitality industry in Zimbabwe. This research makes use of the Processes, Intellectual capital, Culture and Strategy (PICS) model which shows a substantial positive relationship between processes, intellectual capital, culture and strategy and knowledge management. The research was based on case studies of 3 hotels in Zimbabwe. Structured interviews were used to elicit information from managerial employees and questionnaires were administered to non-managerial employees. Stratified random sampling was used to select a total 50 participants mainly 15 managerial and 35 non-managerial staff in the research from all the hotels. The findings from this research revealed that the organisations have in place knowledge management strategies and these lead to development of new ideas, new products and also new ways of doing things that will eventually lead to improve the organizational performance. The main conclusions drawn from this study is that organizations have to learn to exploit their knowledge resource and put them to work to improve their performance. This research recommends that effective knowledge management requires that organizations incorporate knowledge management strategies into their overall business strategies.
\end{abstract}

Keyword: Knowledge Management, hospitality industry, learning organisation, human resource, performance

\section{Introduction}

Sustainable competitive advantage is dependent on building and exploiting core competencies. The ability to develop and leverage the value of these intangible assets comprises a core competency for organization, particularly those providing financial and professional services, Drucker (1998). In knowledge intensive organizations, processing knowledge is central to business success. Due to global competition and new challenges facing business and industry are creating substantial pressures on all organizations. To establish long term competitive advantage from an information and knowledge management point of view it is important to efficiently exploit what the business actually knows and not only what it owns. The researcher tried to show the impact of knowledge management strategies on organizational performance in the hotel industry.

However, Knowledge Management (KM) is actually based on two critical activities which are firstly the capturing and documenting of individual explicit and tactic knowledge, and secondly dissemination within the organization. If these activities are not properly followed it will lead to insufficient, inaccurate or irrelevant knowledge that will inevitably result in a bad decision. On a most basic level the search for greater profit is the driving force behind the recent emphasis on knowledge management since human resource is the important resource in organizations. The hospitality industry covers a wide range of organisations offering food services and accommodation. The industry is divided into sectors according to the skill-sets required for the work involved. Sectors include accommodation, food and beverage, meeting and events, gaining entertainment and recreation tourism services and visitors information. The research therefore looks at three hotels in Zimbabwe.

\section{Literature Review}

According to Armstrong (2006), Knowledge Management (KM) is concerned with storing and sharing the wisdom, understanding and expertise accumulated in an organization about its processes, techniques and operations. Hansen (1999) proposed that hundreds of years ago people who used to own family businesses used to pass their knowledge about the business to their children, master craftsman taught their trades to apprentices and workers exchanged ideas and knowledge about the job. This have led to a shift from natural resources to 
intellectual assets, how access on the knowledge in organizations and on how to use it in improving organization's performance. Knowledge management originated in management science and has been applied successfully in organizations.

The discipline of knowledge management has matured over the past decade, interest in this field eminent from the fact that organizations compete on their knowledge based assets. Since most organizations strive to acquire the most advanced technology asset (within their budget constraints), to hire the smartest people and innovative business processes. That is in each of these efforts successful organizations are able to leverage knowledge in and around thus connect disparate pieces of knowledge and leverage it toward attaining organizational performance, (Desouza \& Paquette, 2011). KM system must first win employees from amongst competing sources, thus attract employee attention as well as providing essential motivation, understanding, desired autonomy and personal information management capability. By having employee participates in a knowledge development lifecycle within which knowledge is initiated, crystallized, shared and applied leading to useful outcomes such as decisions, ideas, plans and innovations so as to contribute organizational performance. For organizations to achieve competitive advantage it depends more than anything than on its knowledge. That is more specific on what it knows, how it uses what it know and how fast it can know something new to influence organization performance. Wright, (2005) allude that knowledge management efforts have long history to include on the job discussions, formal apprenticeship, discussion, discussion forums, professional training and mentoring programs. O'Dell and Grayson (1998) propound that effective KM strategies aim to get the right knowledge to the right people at the right time which enables employees to have relevant knowledge that will lead to improved organizational performance. So there is need for KM strategies to be aligned with the business vision and management must ensure that staff are clearly onboard, so as to ensure understanding of why knowledge is important. There is also need to have channels for discussion and allow a flow of ideas above all trust must be developed between the management and the employees. Wright (2005) argue that, this have lead to growth recognition of knowledge as an asset, as it can be substituted for land or capital and can be a greater force than any of those in production of goods and services.

There is also need to measure how much a KM implementation contributes to business benefits can be challenging because it deals with something intangible. Human resource management practitioners are often requested to provide evidence that KM strategies contribute to organizational performance since it might not be the only factor affecting organizational performance. Holt and Trent (2004) used four metrics to access organizational knowledge including individual, context, content and process knowledge measures. These lead to access the contribution of knowledge to business performance more explicitly and provide valuable insight into how knowledge can be strategically managed. It shows that KM strategies have to demonstrate value and benefits in order to gain support from variety of stakeholders and must be measured using intermediates such as the number of new ideas, number of new products, benchmarking and customer complaints on the contribution of knowledge management activities to organizational performance. Drucker (1993) suggested that productivity of knowledge is the determining factor in the competitive position of a company and its management responsibility to manage knowledge. As witnessed by the increase concentration in recent years on the KM practices of organizations can be seen in the work of Petrash (1996) on intellectual asset management in Dow Chemical Company and the management practice of intellectual capital. Davenport and Prusak (1998) proposed that individual minds are usually embedded with knowledge about organizational routines, processes, practices, systems, software and norms as they have experience in one form or another in organizations. It is also estimated that over forty percent of the U.S. economy is directly attributable to the creation of intellectual capital (Klasson 1999) and over ten percent of the gross domestic product (GDP) in developed countries around the world are reinvested in the development of knowledge in order to out think the competition.

According to Uriarte (2008), Knowledge can be captured in various ways; knowledge from outside the organization can be captured by accessing different sources such as publications, websites, emails and internet. Explicit knowledge from within and outside of the organization can be captured in various forms such as printed reports, record of meeting and copies of memos. These document outputs are generally generated at various stages of operation of the organization. Tacit knowledge can be create and captured during discussions and meetings with office colleagues, stakeholders and consultants. Thus seminars and workshops also provide excellent venues for creating and capturing tacit knowledge that may come from the participants. Nonaka and Takeuchi (1995) distinguished between explicit and tacit knowledge, by suggesting that explicit knowledge is formal knowledge that can be packed as information and can be found in the documents of an organization such as reports, articles, manuals and software e.t.c. and tacit knowledge is personal knowledge implanted in individual experience and is shared and exchanged through direct eye to eye contact. Thus it shows tacit 
knowledge can be communicated in a most direct and effective way whereas explicit knowledge is indirect and similarly of quality.

There are a number of factors that can motivate an organization to establish a formal and systematic management of knowledge. These include the need to get a better insight on how the organization works, reduce the time and effort in searching for information and documents, avoid repetition of errors and unnecessary duplication of work, reduce the response time to questions that are asked frequently and improve the quality and speed of making important decisions. Thus various level of the organization including administrative, tactical and strategic can benefit form a systematic and formal knowledge management. Uriarte (2008) alluded that, administrative benefits include reduction in Human resource management workload, that is better planning of recruitment of employees, personalized training of staff and improvement in the retention of employees and skills. Knowledge management also provides employees with the necessary tools to auto administer their data which would contribute to the organizational performance, (Uriarte 2008). Through KM most organizations can turn knowledge into a strategic asset and create an ever learning organization. It will enable the organization to learn from its self by capturing relevant experiences and making them readily available throughout the organization. By having an efficient knowledge storage system and intelligent distribution process, the whole organization can learn from individuals and from groups working within the organization. This will assist in ensuring that the right persons with relevant knowledge are consulted at the most appropriate time. Snowden (1999) argued that, benefits of sustainable KM include reduced dependencies on knowledge champions, employee reward systems, reduced monitoring and reduced redevelopment. However by effective deployment of these tools within a KM systems can improve collaboration, enhanced competitive advantage, responsiveness and increase overall productivity.

There are also challenges in most organisations including the hospitality industry where employees are reluctant to share their knowledge freely. They feel that their special knowledge is the very reason why they are important to the company and why the organization keeps them employed. Drucker (1999) highlighted that, employees have a tendency to keep the knowledge to themselves, thus becoming valuable to the organization resulting in employment security. However the other biggest challenge to successfully implement KM is to properly address the culture change issue. Since the KM efforts focus on this aspect of organizational change and must develop programs to reach out to individuals involved. These programs include communications, training, polices and procedures and incentives. They must also include knowledge proficiencies, a comprehensive measurement system and it must not be divorced from a business goal. Uriate, (2008) argued on an economic point of view that KM must be considered not as expenditure but as an investment in the efficiency and competitiveness of an organization.

Just like quality precepts becoming embedded in many firms' cultures and daily operating procedures, the best outcome for KM movement will be a similar embedding.KM has become part of everything an organization does and be part of everyone's job. If organizations are successful in managing knowledge leads to reduced dependencies on knowledge champions, employee reward systems and reduced monitoring and redevelopment. Chong and Choi (2005) recommended that employee training, knowledge retention and involvement in decision making process are crucial in KM. Management aim to give employees a sense of security, motivated through incentives, training and empowered with authority to ensure successful KM. It is the success of KM that all stakeholders be involved in decision making process. This shows that strengthening of human element for sharing will promote creativity and innovative thinking. The processes will be developed in alignment with strategies and goals of the organization. Gao and Clarke (2008) highlighted, that thus effective and appropriate utilization of the knowledge resource than competitors will give an organization not only competitive advantage but also help maintain it by constant up gradation of knowledge base, thus KM contribute to organizational performance.

The hospitality industry is facing problems of industrial espionage which is negatively affecting the industry performance and failure to utilize knowledge that is in organizations which adds value to the organization. Therefore, it is of utmost importance to identify KM strategies employed by the industry and their impact on organizational performance. Organization's knowledge is of vital important to the wellbeing of those companies and all companies have the responsibility to nature and protect this critical value adding asset. The Zimbabwean hospitality has gone through a serious phase of economic hardships ranging from poor room occupancies and covers which have affected the expected revenues to a serious flight problem leading to poor service delivery and customer satisfaction. The hospitality industry consists of broad category of fields within the service industry that include lodging restaurants, event planning, transportation and additional fields within the tourism industry. The research is of great importance as it shows how knowledge management leads to improvement of 
the industry performance, gain competitive advantage, innovation, sharing of lessons learned and continuous improvements especially with the global competition and changes that organization are facing. According to the $21^{\text {st }}$ of March 2011 financial Gazette highlighted that Tourism and hospitality industry is expected to become the world's fastest growing sectors between 2011 and 2021 with a growth rate of 6.9 percent per annum and annual earnings of over $\$ 850$ million. The research is therefore of importance since the industry has potential of boosting the economy.

The researcher made use of the Processes, Intellectual capital, Culture and Strategy (PICS) model by Bhatti as proposed in Chong and Choi (2005) shows a substantial positive relationship between processes, intellectual capital, culture and strategy and knowledge management. The model aims at effective integrating of these variables and effective utilization of knowledge. This is also a subs tail positive relationship between knowledge management and organizational performance. Thus the argument of this model is to bring all stakeholders into confidence to evolve a strategy which take all organizational knowledge into consideration and turn it into core competency for a sustained competitive advantage, (Davenport and Prusak, 2000).

\section{Methodology}

The researcher used qualitative research method since it focuses on specific situations or people, (Maxwell 1996).The research was based on people's opinions on the issues of knowledge management. The researcher made use of a case study and according to Bhattacharya (2003) a case study is holistic as the researcher managed to preserve the wholeness, unit and integrity of the environment where the research took place. The research made use of 3 hotels in Zimbabwe in 3 provinces of Zimbabwe, one hotel from the Midlands Province one from Matebeland and one from Manicaland. The names of the hotels will not be revealed due to issues of confidentiality and anonymity. Questionnaires were used for non managerial employees and structured interviews for management which were 15 minutes long. Stratified random sampling was employed were respondents were divided into strata's as there were managerial employees and non-managerial employees as it assist in getting reliable and valid information. A sample size of fifty (50) respondents was used out of a total population of 200 in the in all the 3 hotels. The respondents included 15 managerial and 35non-managerial employees. Primary and secondary sources of data where used in the research. The researcher used the thematic method in data analysis were themes were derived from the objectives. The research was limited to the hospitality industry and further research on other industries in Zimbabwe can be of benefit.

\section{Findings and Discussion}

The findings below were derived from the questionnaires distributed to non managerial employees and the interviews carried out by managerial employees. As alluded earlier the data collected was arranged into themes based on the objective of the research.

\subsection{Knowledge Management Strategies Employed}

\subsubsection{Reward and Recognition Policy}

It was pointed out by $80 \%$ of the managerial staff from the interviews conducted in all the hotels that reward and recognition is one of the strategies employed by the organisation in knowledge management. The researcher found that hospitality industry has established a reward and recognition policy in order to facilitate KM. The fact that the organization has a sound reward and recognition policies, they managed to attract, retain and motivate employees and this contributes to new idea generation through team working and retain the existing knowledge. This enabled the organization to have a crop of innovative workforce which contributed to increased organizational performance. Through such strategy it provides a means of facilitating knowledge sharing within the organization. For organizations to nature creativity they need to reward employees in such a way that they have a stakeholder interest in the innovative outcomes. Maryam and Dorothy (1999) suggested that ,a sound reward and recognition policy will lead to increased knowledge content in the development and provision of products and services hence increased organizational performance. The researcher found out that reward and recognition actually encourages employee commitment and this enhances creation of innovative ideas and management of knowledge which benefits the organization in the long run in terms of improved organizational performance. Evans (2003) suggested that, reward and recognition enable individuals to demonstrate a commitment to continuous learning to be awarded extra learning time, which could be used to invest in further learning.

\subsubsection{Training and Development}

The researcher found out that the industry has a culture of training and development which enable employees to continuously acquire more knowledge, abilities and experience, this was pointed out by $75 \%$ of non-managerial 
from the questionnaires distributed and all the managerial staff. Thus by having initiatives such as training and development, employees will be able to adapt to any changes, challenges or new demands in the organization processes. These strategies are important for organizational performance. Skimmer (2002) supported this by saying KM strategies enable and support effective delivery of organization mission, developing a learning culture that values the importance knowledge and encourage innovation by creating an open and transparent environment with good practice and document management and sharing appropriately. The researcher noted that investing in training brings higher returns than investment capital. Since a $10 \%$ increase in individual development can be associated with a 9\% gain in productivity. However Steward (1998) suggested a model that showed good human capital management is linked to organizational performance since when one gain new knowledge the is behavioral change which will benefit the organization as illustrated below:

\subsubsection{Communication/Open Door Policy}

It was clear from questionnaires and interviews, that open door policy facilitates KM within the organization and is one of the strategies. This was allude by $95 \%$ of management and $70 \%$ of the non managerial employees. As there is freedom for each and every employee to share new ideas that he/she might be having which aids in improvement of organizational performance. Nonaka and Takeuchi (1995) argued that, open communication channels, listening to all levels of the organization and individual of all grades are some of the key elements of a high performance organization. The researcher also found out that communication facilitates knowledge exchange and dissemination which yields competent workforce that contribute to the overall organizational performance. Maison and Rudd, (2001) supported this by saying that communication is a critical factor in KM and business ability to create and maintain a distinctive core competencies. More over the researcher noted that respondents who were not aware of KM strategies can be attributed that the leadership is not communicating strategies such as open door policy and the organizations are not practicing consultative meetings. Armstrong, (2006), highlighted that there is need to have strategies well known to all employee so as to facilitate KM by having employees with the right knowledge and skills and also safe guard knowledge of the organization. The researcher found out that by having open door policy it enable employee to share a common vision, take ownership of shared objectives and they will feel they played a part in success of the organization.

\subsection{Impact of Knowledge Management on Organizational Performance}

The researcher found out that KM has positive impacts on the industry's performance as a whole since all the respondents acknowledged that knowledge management aids in achievement of organizational performance. It was argued by $50 \%$ of the managerial staff that they calculate the return on investment (ROI) in determining the impact of KM on organizational performance as it helps in assessing the financial performance of the initiative of knowledge management such as training and development. The managerial employees pointed out that number of new ideas; new products and job satisfaction are the only effective indicators to use in measuring the impact of knowledge management. $40 \%$ of the non-managerial employees said it is through knowledge management strategy that an organization identifies the knowledge required to execute the firm's strategy by comparing its actual knowledge and recognize its strategic knowledge gaps. They also argued that if an organization KM's strategy matches with the business strategy, the impact of knowledge is positive. Of the nonmanagerial employees, $45 \%$ agreed that knowledge management contribute to the achievement of organizational performance. One finance employee pointed out that it is through knowledge management that accurate financial information and meeting deadlines are met. Performance management reports in all the hotels indicated that $10 \%-15 \%$ of the overall performance is attributed to KM which shows that at SZL they practice knowledge management and recognize its impact on financial performance. Davenport and Prusak, (1998), highlighted that knowledge is an asset of the organization and its effective utility is the core competency that bring the desired results such as improved organizational performance. The full potential of an organization's employees is best released through shared values and a culture of trust and empowerment, which encourages the involvement of everyone.

The researcher found that in order to manage knowledge, it must be measured so as to provide evidence that knowledge initiatives contribute to corporate objectives. More so, in order to access the impact of knowledge management on organizational performance there is need to use indicators to measure the impact of knowledge management on organizational performance such as benchmarking based on performance. Ahn and Chang, (2004), suggested that there is need to provide a way to assess the contribution of knowledge to business performance by employing products and processes as indicators. Holt, et al (2004) also highlighted four metrics to access organizational knowledge, including individual, context, content and process knowledge measures. 
The researcher also found out that there are other factors that affect performance such as competitive environment and industrial conditions so it shows that when analyzing performance of an organization there is need to consider other factor rather than considering knowledge only. According to Smith and Lyles (2011) suggested that one can use the perspective of the knowledge based view to show a positive link between knowledge and performance, as it is expected that a particular sub-category of knowledge which is valuable, rare and non substitutable would lead to competitive advantage. Knowledge management should not work in isolation for effective organizational performance. There are other factors that should be considered for effective organizational performance. The findings suggest that knowledge which is relevant have positive effect on organizational performance. Evans, (2003), highlighted that it is important for KM to be done by encouraging involvement and participation of all employees so that they get the sense of what managing knowledge means in the context of an organization including behaviors that are most valued. The researcher found out the following indicators to assess the impact of KM on organizational performance. Through the interviews $80 \%$ of managerial employees found out that training and development programmes are as an important means to transform the outlook of employee by enriching working environment with higher levels of staff retention as well as increased productivity and performance. The researcher noted that the main objective of training programmes is to reinforce the new knowledge beyond the session and the practical domain. This is best achieved by creating space for the participants to learn from one another as it will lead to creation of behavioral and performance changes in employees resulting in positive impact on the organizational bottom line.

Information from the questionnaires and interviews all revealed that new idea development shows an impact of knowledge on performance as it leads to use of new initiatives such as use of smart phone by the hotel agencies to contact and inform clients about range of services offered and promotions. The researcher found out that new ideas development and new processes have lead to better products and services delivery like quick supply of services and meeting of objectives. Foray and Lundval, (1996), suggested that the key to economic success is always linked to the advances in knowledge creation and the ability of an organization in translating knowledge into products and services that improve organizational performance. Haugh, (2002) suggested that there is need to incorporate return on investments in assessing the contribution of training programmes they would have conduct to see what really has it contributed to the overall performance of the organization in terms of new ideas generated. The researcher noted that there is need to conduct knowledge audits as they highlight which information is currently being created in fact adds no value. This shows the only way to demonstrate KM's value creation to organizational is through new ideas that lead to new products. The PICS model suggest that the is need to take advantage of the organizational knowledge ahead of competitors and make knowledge obsolete before competitors, (Malhotra, 2003).

\subsubsection{Retention Rate}

Information from the $85 \%$ of the management interviewed showed that retention rate can be used to show the impact on KM which will affect organizational performance. Armstrong, (2010), supported this by saying that the turnover of key employees can have a disproportionate impact on the business and the employee's organizations wishes to retain are probably the ones most likely to leave. The researcher noted that the hospitality industry has managed to retain knowledge and skilled workforce through use of monthly incentives for employees, educational assistances for employees who are motivated to improve their careers, paying in kind for example begin offered three cases of Mazoe for each employee and also market driven salaries above it competitors enable the organization to retain its knowledge employees.

\subsubsection{Customer Complaints}

From the researcher customer complaints records shows the impact of knowledge on performance especially after training of employee in sales and marketing department. By training employees on how to deal with different customer leads to decrease in complaints and improve service delivery. This is supported by Dibella and Gould, (2000) who stated that learning organizations can keep their customers by providing skills, competencies and climates which meet existing customer requirements and help to attract new customers and market. This shows that KM have an impact on performance since it leads to increased market share and the bottom line by equipping employees with the necessary skills and competencies that result in competitive way of handling customers since they are critical to the business success. Training of waiters is essential for the organization since it help in improving quality service delivery, customer satisfaction; improve their morale, business development and profitability. From the research in 2009 customer complaints were so high may due to the fact that employees lacked necessary skills and knowledge required to deal with customer but by 2011 the training and development done in the sale and marketing department increased this lead to a reduction in 
customer complaints this shows that knowledge have a positive impact on organizational performance since it lead to decrease in customer complaints and increase in profits in the industry.

\section{Recommendations}

Having understood the concept of KM is the driver of productivity, competitive advantage and managing intellectual capital. The researcher recommends that in order for the hospitality industry to achieve this there is need for management to align KM strategies to business strategies as this will led to accelerated growth, drive individual and organizational learning and create benefits for shareholders. This will help in advances knowledge creation and the ability of the hospitality industry in translating knowledge into products and services. Having a thorough understanding of the concept of the impact of KM strategies on organizational performance. The management must reward (financially or non-financially) since there is evidence that rewards have a strong impact on employee performance. As evidenced from the research, when employees receive rewards and recognition the overall organizational performance increased and new ideas are generated. More so, rewards have a positive impact in promoting KM organizations.

\section{Conclusion}

From the research findings it clearly shows that knowledge management have an impact on organizational performance so it is worth investing in knowledge management because of the benefits associated with it. Since by effectively applying their knowledge would result in reduced costs, better service and products to customers and a gain a distinct competitive advantage in the market place. There is also need to have a holistic strategy which will embrace all aspects of the organization towards the transforming into a knowledge centric organization. By having knowledge employees it assist the organizations to have innovative ideas that will improve on the organizational performance as a whole.

\section{References}

Ahn, \& Chang. (2004). Assessing is contribution of knowledge to business performance, the KP3 methodology. Decision systems, (36), 407-416.

Armstrong, M. (2006). Human Resources Management practices (10th ed.). McGraw-Hill: London.

Bhattacharya, D. (2003). Research Methodology. Anaraga Join: New Delhi.

Chai, K., \& Gregory, M. (2003). Bridging Islands of knowledge: It's a framework of knowledge sharing mechanism. International journal of technology management, (3), 445-460.

Chan, H., \& Ahmen, H. (2003). Knowledge management in business. Human Resources Management Journal, 13(4), 119-126.

Chong, S., \& Choi, Y. (2005). Critical factors in the successful implementation of knowledge management. J Know: Manage Practice.

Davenport, T., \& Prusak, L. (2000). Working Knowledge: How organizations manage what they know. Howard.

Desouza, K., \& Paquette, S. (2011). An Introduction to Knowledge Management. New York: Neal-Schuman Publishers.

Drucker, P. (1999). Management Challenges for the $21^{\text {st }}$ Century. New York: Harper Collins.

Foray, D., \& Lundval, B. (1996). The knowledge based economy from the economics of knowledge to the learning economy. In employment and growth in the knowledge based economy. Paris.

Fowler, F. J. (1984). Survey Research Methods, Thousand Oak. London: SAGE Publication.

Gao, F., \& Clarke, S. (2008). Knowledge management and organizational performance. Journal of knowledge management, (12), 3-17. http://dx.doi.org/10.1108/13673270810859479

Gates, B. (1999). Business at the speed through succeeding in the digital economy. Penguin Books Ltd.

Gubman, E. (1998). The talent solution: Aligning strategy and people to archive extraordinary results. London: Mc Grawhill.

Guy, M. (1994). Organizational Architecture, Gender and Women careers. Review of Public Personnel Administrations, (14), 119-126.

Hall, M., \& Hall, C. (2002). Human Resource Management in knowledge economy: New Challenges, new roles, new capability. New York: Bernet Koehler Publishers.

Hamel, J., Dofour, S., \& Fortin, D. (1993). Case Study Methods. Newbury Park CA: Sage. 
Hauschild, S., \& Stein, W. (2001). Creating a knowledge culture. Mckinsey Quarterly, (4), 23-27.

Holt, D., Bartezak, J., \& Trent, M. (2004). The Development of an instrument readiness for Knowledge Management. Big Island: IEEE Press.

Huberman, A., \& Miles, M. (2002). The Qualitative Researchers Champion. London: SAGE Publications.

Klasson, K. (1999). Managing Knowledge for Advantage: Content and Collaboration Technologies. The Cambridge Information Network Journal, (5), 56-67.

Lindlof, T., \& Taylor, B. (2000). Qualitative Communication Research Methods (2nd ed.). London: SAGE Publications.

Maxwell, J. (1996). Quantitative Research Design. London: SAGE Publications.

Meyer, M., \& Botha, E. (2000). Organisation Development and Transformation in South Africa. Durban: Butterworth Publishers.

Nahpiet, J., \& Ghoshal, S. (1998). Social capital, intellectual capital and the organizational advantage. Academy of management review, 23(2), 642-652.

Nevill, G., \& Pennicott, A. (1990). Women in the workforce: The effect of demographic changes in the 1990's. London: SAGE Publications.

Nonaka, I., \& Takeuchi, H. (1995). The Knowledge Creation Company. New York: Oxford University Press.

O'Leary, D. (1993). Using AI in knowledge management: knowledge bases and anthologies. IEEE Intelligent systems, (13), 34-39.

O'Leary, Z. (2004). Guide to Doing Research. London: SAGE Publications.

Prusak, L. (1997). Knowledge in Organizations. Boston: Butterworth Publications.

Raymond, D. (2006). Knowledge management Forum. Qualitative Social Research, 7, 65-68.

Scase, R. (2002). Living in the corporate zoo: life and work in 2010. Capstone Publishing Limited.

Senge, P. (2002). The leader new work building learning organizations. In H. Mintzberg (Ed.), the Strategy Process. New York: Prentice Hall.

Skimmer, D. (2002). Creating the knowledge based business. Canada: Toronto Publishers.

Steward, T. (1998). Intellectual capital-The wealthy of organizations. London: Nicholas Brealey Publishing.

Teruya, A. (2004). Measuring performance improvements: A knowledge management perspective, Performance improvement. Business Journal, 43(4), 134-143.

Tsoukas, H., \& Mylonopoulos, N. (2004). Organizations as knowledge systems. New York: Palgrave MacMillan.

Ulrich, D. (2000). Human Resource in the New Millennium: Intangibles deliverable and capability. Paris: Human resource World Conference.

Uriarte, F. (2008). Introduction to Knowledge Management. Jakarta Indonesia: A SEAN Foundation.

Van der Spek, R., \& Kingman, J. (1999). Achieving successful knowledge management initiatives. In Liberating knowledge, CBI Business Guide.

Wright, E. (2005). Personal Knowledge, supporting individual knowledge worker performance._Knowledge management Research and Practice, (3), 56-67. http://dx.doi.org/10.1057/palgrave.kmrp.8500061

Yin, R. (2009). Case Study Research: Design and Method (4th ed.). California: SAGE Publications. 